\title{
Stiren-Butadiyen-Stiren İçeriğinin Bitümün Kırılmış Yüzey Morfolojisine Etkilerinin İncelenmesi
}

\author{
Derya KAYA ÖZDEMIR \\ Dokuz Eylül Üniversitesi, Fen Bilimleri Enstitüsü, İzmir, Türkiye \\ d.kaya@deu.edu.tr
}

(Geliş/Received: 06/02/2020;

Kabul/Accepted: 14/08/2020)

\begin{abstract}
Öz: Ülkemizde ve dünyada en sık kullanılan polimer katkısı Stiren-Butadiyen-Stiren (SBS), bitümlü malzemelerde moleküller arası çapraz bağlanmaları oluşturmakta ve bu da bitüm yapısında yapısal, kimyasal, reolojik ve morfolojik vb. farklılıklara yol açmaktadır. Çalışma kapsamında, Taramalı Elektron Mikroskobu (SEM) kullanılarak Polimer Modifiye Bitümün (PMB) kırılmış yüzey morfolojilerinin farklı oranlarda SBS kullanımıyla değişimleri incelenmiştir. Farklı oranlarda SBS kullanımının bitüm içerisindeki şişme oranları Floresan mikroskop (FM) ve Image J Programı kullanılarak araştırılmış ve sonuçlar bitümün çapraz bağ oluşumları ile ilişkilendirilmeye çalışılmıştır. Ek olarak, numuneler Dönel İnce Film Halinde Isıtma (RTFO) deneyi ve Basınçlı Yaşlandırma Kabı (PAV) kullanılarak uzun dönem yaşlanmaya maruz bırakılmış, moleküller arası bağların zarar görmesi sağlanmıș ve bunun yüzey morfolojik görüntüler üzerindeki etkisi incelenmiștir. Sonuç olarak, SBS miktarının \% 5 'den fazla kullanılması durumunda daha yüksek malten içeriğindeki bitümlerin kullanılması gerektiği ve PMB numunelerinin saf bitüme oranla çapraz bağlanmalardan kaynaklı olarak daha pürüzlü kırılmış yüzey morfolojisine sahip olduğu bulunmuştur. Uzun dönem yaşlandırılan numunelerde ise, moleküller arası bağların zayıflamasından kaynaklı olarak daha pürüzlü kırılmış yüzeyler elde edilmiştir.
\end{abstract}

Anahtar kelimeler: Polimer modifiye bitüm, SBS, morfoloji, SEM, Floresan optik mikroskop.

\section{Investigation of the Effects of Styrene-Butadiene-Styrene Content on Bitumen Cracked Surface Morphology}

\begin{abstract}
Styrene-Butadiene-Styrene (SBS), which is the most commonly used polymer in Turkey and all around the world, creates cross-linking between molecules and it causes many differences in bitumen's structural, chemical, rheological and morphological characteristics. Within the scope of the study, the changes of Polymer Modified Bitumen (PMB) cracked surface morphology depending on different content of SBS usage were investigated using the Scanning Electron Microscope (SEM). In addition, the volumetric changes of altering SBS content in the PMB is examined by Fluorescent optical microscopy (FM) and Image J Program. The results are investigated with the cross-linking occurrence due to the SBS modification. In addition, samples were subjected to long-term aging using Rotational Thin Film Oven (RTFO) Test and Pressure Aging Vessel (PAV), in order to damage the molecular internal bonds and the effects of aging on cracked surface morphological images are examined. As a result, it is possible to say that, higher amount of maltene fraction is required to use more than 5\% of SBS content. PMB samples have more rough cracked surface morphology due to cross-linking compared to neat bitumen. Long term aged samples had more rough cracked surfaces due to the damages in intermolecular bonds.
\end{abstract}

Key words: Polymer Modified Bitumen, SBS, morphology, SEM, Fluorescent optic microscopy.

\section{Giriş}

Bitüm, 1sıtıldığında sıvı hale gelen ancak oda sıcaklığında katı halde bulunan termoplastik davranışa sahip kompleks organik moleküllerin (temel Hidrokarbon, minör Oksijen, Nitrojen, Kükürt) birleşiminden oluşan bağlayıcı bir malzemedir. Bitüm ham petrolden elde edilir ve ayrıca maltenler (Doymuş yağ + Aromatik + Reçineler) ve Asfaltenlerden oluşmaktadır (DARA) [1-4]. Asfaltenler, yüksek polar malzemeler olarak kabul edilir ve diğer bileşenlerle karşılaştırıldığında en yüksek moleküler ağırlığa sahiptirler ve bitümün elastik davranışından sorumludurlar [5]. Maltenler ise kauçuklar veya polimerler tarafından emilen ve bitümün viskoz davranışından sorumlu olan bileşenlerdir [6].

\footnotetext{
* Sorumlu yazar: d.kaya@ @eu.edu.tr. Yazarın ORCID Numarası: 0000-0003-1517-9405
} 
Günden güne ilerleyen asfalt teknolojisi ile birlikte istenilen özelliklerde asfalt kaplaması üretebilmek mümkündür. Bu sebeple, dünyanın birçok yerinde olduğu gibi Türkiye'de de, kullanılacağı bölgenin koşullarına göre asfalta istenilen özellikleri kazandıran polimer katkılar sıkça uygulanmaktadır. Bitümün polimer katkılar ile modifikasyonu sonucunda oluşan Polimer Modifiye Bitüm (PMB), asfaltın mekanik ve termal özelliklerini iyileştirmek, bakım ve onarım masraflarını düşürmek gibi birçok avantajı sayesinde uzun yıllardır katkı malzemesi olarak kullanılmaktadır [3, 7-10]. Stiren-Butadiyen-Stiren (SBS), bitüm gibi termoplastik malzemelerle kullanılabilen elastomerik bir polimer katkısıdır. SBS, düşük sıcaklıklarda çatlama direncini, yüksek sıcaklıklarda ise tekerlek izi direncini arttırması sayesinde PMB teknolojisinde Türkiye'de ve dünyada en yaygın kullanılan kopolimerlerden biridir [11-17]. SBS esnek polibütadien (PB) matrisinde (sürekli faz) bulunan sert polistiren (PS) domenlerinden (dağılmış faz) meydana gelen Stiren-Butadien triblok zincirlere sahip kopolimerlerdir [18] (Şekil 1).

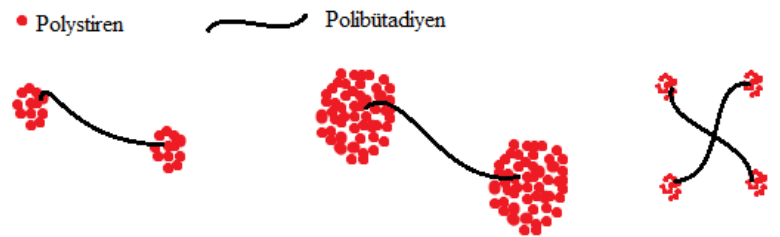

Şekil 1. Farklı oranlarda PS ve PB içeren SBS polimerlerinin şematik gösterimleri.

SBS kopolimerinin polibütadien matrisi bitümün malten bileşenlerini emerek orijinal hacminin 9-10 kata kadar şişmesine sebep olmaktadır. PB blokları bitümün doymuş yağ bileşenleri, PS blokları ise bitümün aromatik bileşenleri ile benzer çözünürlük parametrelerine sahip olmalarından dolayı tepkimeye girerek şişerler [3, 6, 19]. Malten / asfalten oranı, modifiye asfaltın SBS ile modifikasyonu sırasında önemli bir parametredir [20]. Bitüm içeriğindeki malten oranının, polimer ile daha iyi bir işlenebilirlik yaratması açısından belirli bir değer aralığında olması gerekmektedir. SBS'nin bitüm ile karıştırılmasıyla, polistiren (PS) uç blokları üç boyutlu bir ağ oluşturarak fiziksel olarak çapraz bağlanırlar (Şekil 2). Bu çapraz bağlar, SBS miktarı, bitüm özellikleri ya da stiren/butadiene oranı gibi birçok parametreye doğrudan bağlıdır [21].

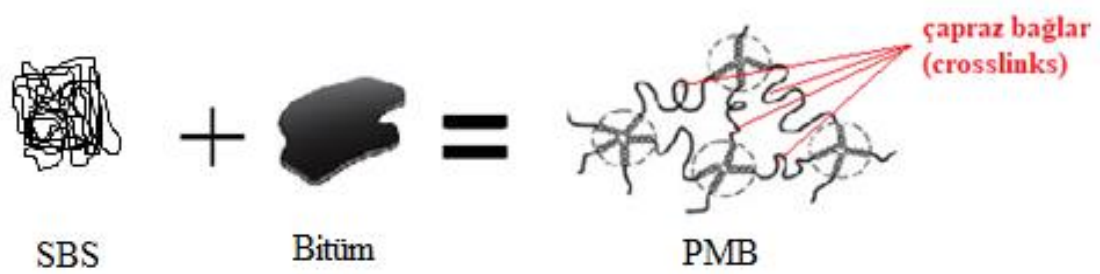

Şekil 2. PMB içeriğinde oluşan çapraz bağların gösterimi

PMB içeriğindeki katkı türleri ve miktarları bitüm fazı içeriğindeki çapraz bağ dağılımlarını etkilemekte ve bu durum Taramalı elektron mikroskobu (SEM) kullanılarak incelenebilmektedir [22]. Önceki çalışmalar göstermiştir ki, saf bitümün kırılan yüzeyinin SEM altındaki morfolojik görüntüleri pürüzsüz, homojen ve devamlıdır [23]. Polimer katkılı numunelerde polimer ve bitüm arasında oluşan çapraz bağlar ile birlikte saf bitüme kıyasla daha fazla bağ bulundurdukları için, PMB numuneleri kırılma durumunda daha pürüzlü yüzey sağlamaktadırlar [24]. Bu bilgiye dayanarak, farklı miktarda polimer içeren bitümlerin, içeriklerindeki bağ miktarları göz önünde bulundurulduğunda, yüzey morfolojilerinin de değişken olmasını beklemek mümkündür.

Kumar ve arkadaşları Hindistan'da 2016 yılında gerçekleştirdikleri çalışmada, farklı penetrasyon sınıfına ait bitümler kullanılarak SBS kopolimerinin bitüm fazı içerisinde dağılımı ve farklı bitüm sınıflarının bu dağılım üzerindeki etkileri araştırılmıştır. Elde edilen sonuçlara göre, bitümün penetrasyon sınıfının artması ile yüzey morfolojisinin pürüzlülügü azalmaktadır. Buna sebep olarak, penetrasyon sınıfının artmasıyla birlikte bitümlü malzemelerin viskoz davranışının artmasını ve kırılma yüzeylerinin de bu oranda daha hızlı toparlanmasını göstermek mümkündür. Aynı çalışmada, daha yüksek penetrasyon sınıfına ait bitümün SBS ile polimerizasyonu sonucunda daha pürüzlü bir yüzey morfolojisine sahip olduğu görülmüştür. Bunun sebebi, yüksek penetrasyon sınıfina ait numuneler içeriğinde daha yüksek aromatik bileşen içermekte, bu da SBS ile daha çok tepkimeye girmesini sağlamaktadır. Böylece, SBS hacmindeki artış kırılma yüzeylerinin daha pürüzlü olmasını sağlamaktadır [25]. 
Bitümlü numunelerin yüzey morfolojisini etkileyen bir diğer parametre de malzemelerin yaşlanma özellikleridir. Kırılma çizgileri, malzemenin zayıf noktalarını, yani moleküllerin bağlanma noktalarını takip etmektedir. Bu durumda, yaşlanmanın sonrasında bağları zarar görmüş numunelerin kırılmalarının ardından yüzey morfolojilerinin de daha pürüzlü olduğu görülmüştür [26].

Çalışma kapsamında, PMB üretiminde farklı oranlarda (\%4-5-6) SBS kullanımının ve PMB içeriğinde oluşturduğu çapraz bağların etkilerinin, numunelerin kırılmış yüzey morfolojileri üzerindeki değişimleri SEM kullanılarak araştırılmıştır. Ayrıca PMB içeriğindeki nihai şişen SBS hacminin oluşan bağ yapıları üzerindeki olası etkileri, floresan optik mikroskop ve görüntü işleme teknikleri kullanılarak incelenmiştir. Son olarak, numuneler Dönel İnce Film Halinde Isıtma (RTFO) Deneyi ve Basınçlı Yaşlandırma Kabı (PAV) kullanılarak uzun dönem yaşlanmaya tabi tutulup moleküler bağlarının zarar görmesi sağlanmış ve bu durumun kırılmış yüzey morfolojisi üzerindeki etkileri değerlendirilmiştir.

\section{Deneysel Çalıșmalar}

\subsection{Malzemeler}

Deneysel çalışmalarda TÜPRAŞ Aliağa rafinerisinden temin edilen 50/70 penetrasyon sınıfi bitüm kullanılmıştır. Kullanılan bitüme ait DARA (doymuş yağ, aromatikler, rezin ve asfalten) Analizi sonuçları Tablo 1 'de verilmiştir. Ayrıca, saf bitüm üzerinde; penetrasyon, yumuşama noktası, özgül ağırlık, parlama noktası vb. geleneksel bitüm deneyleri ve Brookfield Dönel Viskozimetresi (RV) kullanılarak viskozite deneyi uygulanmıştır. Elde edilen sonuçlar Tablo 2'de sunulmuştur.

Tablo 1. Saf bitümün DARA analizi sonucu

\begin{tabular}{llll}
\hline Doymuş Yă̆ (\%) & Aromatikler (\%) & Rezinler (\%) & Asfaltenler (\%) \\
\hline 8,76 & 66,37 & 9,84 & 15,03 \\
\hline
\end{tabular}

Tablo 2. Saf bitümün geleneksel laboratuvar deney sonuçları

\begin{tabular}{|c|c|c|c|}
\hline Deney & $\begin{array}{l}\text { ASTM Standardı } \\
\text { TS EN Standardı }\end{array}$ & Sonuçlar & Limitler \\
\hline Penetrasyon $\left(25^{\circ} \mathrm{C} ; 0,1 \mathrm{~mm}\right)$ & $\begin{array}{c}\text { ASTM D5/D5M-13 } \\
\text { TS EN } 1426\end{array}$ & 55 & $50-70$ \\
\hline Yumuşama Noktası $\left({ }^{\circ} \mathrm{C}\right)$ & $\begin{array}{c}\text { ASTM D36/D36M-12 } \\
\text { TS EN } 1427\end{array}$ & 49 & $46-54$ \\
\hline \multirow{4}{*}{$\begin{array}{l}\text { Viskozite }\left(135^{\circ} \mathrm{C}\right) \\
\text { Dönel İnce Film Halinde Isıtma Deneyi } \\
\text { (RTFOT) sonrası: } \\
* \text { Kütle Değişimi }(\%)\end{array}$} & ASTM D4402/D4402M-13 & 412,5 & - \\
\hline & ASTM D 2872 & & \\
\hline & TS EN 12607-1 & - & - \\
\hline & - & 0,04 & 0,5 (maks.) \\
\hline * Penetrasyon Değeri & $\begin{array}{c}\text { ASTM D5/D5M-13 } \\
\text { TS EN } 1426\end{array}$ & 51 & 50 (min.) \\
\hline *Yumuşama Noktas $1\left({ }^{\circ} \mathrm{C}\right)$ & $\begin{array}{l}\text { ASTM D } 2872 \\
\text { TS EN } 1427\end{array}$ & 54 & 48 (min) \\
\hline Düktilite $\left(25^{\circ} \mathrm{C} ; \mathrm{cm}\right)$ & $\begin{array}{l}\text { ASTM D113-07 } \\
\text { TS EN } 13589\end{array}$ & 121 & $>100$ \\
\hline Özgül Ağırlık & $\begin{array}{l}\text { ASTM D70-09e1 } \\
\text { TS EN } 15326\end{array}$ & 1,03 & - \\
\hline Parlama Noktas $1\left({ }^{\circ} \mathrm{C}\right)$ & $\begin{array}{l}\text { ASTM D92-12b } \\
\text { TS } 123 \text { EN 22592 }\end{array}$ & +260 & $230(\min )$ \\
\hline
\end{tabular}

Deneysel çalışmalarda kullanılan D 1192 SBS kopolimeri Kraton ${ }^{\circledR}$ Polimers/Hollanda'dan temin edilmiştir. Tablo 3'de SBS kopolimerine ait moleküler ağırlık değerlerini belirlemede kullanılan GPC (Jel Geçirgenlik Kromatografisi) deneyi sonuçları verilmiştir. 
Tablo 3. SBS kopolimerinin moleküler ağırlık sonuçları

\begin{tabular}{ccccccc}
\hline $\begin{array}{c}\text { Mp (g/mol) } \\
\text { Tepe } \\
\text { moleküler } \\
\text { ağırlık }\end{array}$ & $\begin{array}{c}\text { Mn (g/mol) } \\
\text { Ozmotik } \\
\text { Basınç son } \\
\text { grup } \\
\text { analizi }\end{array}$ & $\begin{array}{c}\text { Mw } \\
(\mathbf{g} / \mathbf{m o l}) \\
\text { Işı } \\
\text { saçılması }\end{array}$ & $\begin{array}{c}\text { Mz (g/mol) } \\
\text { Sedimentasyon } \\
\text { dengesi }\end{array}$ & $\begin{array}{c}\text { Mz+1 } \\
(\mathbf{g} / \mathbf{m o l}) \\
\text { Ekstrüzyon } \\
\text { değeri }\end{array}$ & $\begin{array}{c}\text { Mv } \\
(\mathbf{g} / \mathbf{m o l}) \\
\text { Viskozite }\end{array}$ & $\begin{array}{c}\text { Po } \\
\text { Polidispersite } \\
\text { indeksi }\end{array}$ \\
\hline 162217 & 151970 & 165267 & 181287 & 205128 & 178424 & 1.087498 \\
\hline
\end{tabular}

\subsection{SBS Polimer Modifiye Bitüm Üretimi}

Türkiye'de ve dünyada SBS katkılı PMB üretiminde yaygın olarak katkı oranı bitüm ağırlığının \%5'i olarak kullanılmaktadır. Çalışma kapsamında, karışımdaki SBS oranı değişiminin PMB hacminde SBS dağılımı ve kırılmış yüzey morfolojisine etkisini ortaya koymak amaçlandığı için \%5土1 SBS içeren PMB numuneleri incelenmiştir. Polimer modifiye bitüm örnekleri, bitüm ile farklı oranlardaki (\%4, 5 ve \%6) SBS kopolimerleri sabit karıştırma koşulları (sıcaklık $175 \pm 5^{\circ} \mathrm{C}$, karıştırma süresi $30 \mathrm{dk}$. ve karıştırma hızı $2000 \mathrm{rpm}$ ) altında üretilmiştir. Son olarak numuneler, yaşlanmanın kırılmış yüzey morfolojik görüntüler üzerindeki etkilerinin incelenebilmesi amacıyla önce kısa dönem ardından ise uzun dönem yaşlandırma işlemine maruz bırakılmışlardır.

Bitümlü malzemelerde yaşlanma, bitümün karıştırma ve sıkıştırma süresi ya da hizmet ömrü boyunca gerçekleşmektedir. Yaşlanma esas olarak iki aşamada oluşmaktadır. Malzemenin maruz kaldığı ilk yaşlanma, kısa süreli yaşlandırma olarak adlandırılır ve karıştırma sıkıştırma süresince asfaltta uçucu madde kaybı ile ilişkilidir. İkinci tür yaşlanma ise, uzun süreli yaşlandırma olarak adlandırılan malzemenin servis ömrü süresince kademeli olarak oksidasyona uğramasıyla ilişkilidir [27]. Kısa dönem yaşlanma laboratuvar ortamında Dönel İnce Film Halinde Isıtma Deneyi (RTFOT) ile uzun dönem yaşlanma ise Basınçlı Yaşlandırma Kabı (PAV) kullanılarak simüle edilebilmektedir [27].

RTFOT (ASTM D2872-12, 2012): Bu deney, $163^{\circ} \mathrm{C}$ sicaklığa sahip etüve yerleştirilen 8 adet cam şişe kullanılarak yapılmaktadır. Her bir behere 35 gram asfalt çimentosu doldurulur. Düş̧ey eksende dakikada 15 devir yapacak şekilde 85 dakika süreyle döndürülmektedir. Dönme esnasında deney aletinin tabanında bulunan bir hava üfleyici yardımıyla numune kaplarına, akışı $4000 \pm 200 \mathrm{~mL} /$ dak. olacak şekilde hava verilmektedir. Sıcaklığın etkisiyle bitüm, kapları tam olarak kaplayarak ince bir film tabakası oluşturmakta, hava üfleyici sayesinde de bitümün kısa dönem yaşlanması sağlanmaktadır.

PAV (ASTM D6521-05, 2005): Basınçlı yaşlandırma kabı deneyi, 50 gr. kısa dönem yaşlandırılmış bitümün $140 \mathrm{~cm}$ çapında kaplara boşaltılması ve bu kapların önceden isıtılmış PAV cihazlarına yerleştirilmesi ile başlamaktadır. Sıcaklık $\pm 2{ }^{\circ} \mathrm{C}$ hassasiyete dayanarak ayarlanmalı ve kullanılacak bağlayıcının kıvama göre 90 , 100 veya $110^{\circ} \mathrm{C}$ değerlerinden biri seçilmelidir. Deney 20 saat süreyle $2,10 \mathrm{MPa}$ basınçlı hava kullanılarak uygulanmaktadır. 20 saat sonra basınç boşaltma işlemi 8-10 dakika sürecek şekilde tedricen boşaltılır. Ardından numuneler cihazdan çıkarılarak $163{ }^{\circ} \mathrm{C}$ da 30 dakika etüvde tutularak içinde hapsolan hava uzaklaştırılır ve etüvden alınan numuneler DSR cihazında kullanılmak üzere saklanır. Bu şekilde bitümde uzun dönemde ortaya çıan fiziksel ve kimyasal değişiklikler temsil edilmektedir [28].

Deneysel sonuçlar kısmında her bir numune yaşlanma durumu ve içeriğindeki SBS miktarı göz önünde bulundurularak kısaltmalar ile anılmıştır. Çalışma kapsamında kullanılan kısaltmalar, malzeme yaşlanma özellikleri ile birlikte Tablo 4'de sunulmuştur.

Tablo 4. PMB ve saf bitüm numunelerinin karıştırma koşulları ve yaşlanma durumları

\begin{tabular}{ccc}
\hline Numune Adı & İçeriğindeki SBS miktarı (\%) & Yaşlanma durumu \\
\hline$\% 4-U A$ & 4 & Yaşlandırılmamış \\
$\% 5-U A$ & 5 & Yaşlandırılmamış \\
$\% 6-U A$ & 6 & Yaşlandırılmamış \\
NB-UA & *saf bitüm & Yaşlandırılmamış \\
$\% 4-A$ & 4 & Uzun dönem yaşlandırııış \\
$\% 5-A$ & 5 & Uzun dönem yaşlandırılmış \\
$\% 6-A$ & 6 & Uzun dönem yaşlandırılmış \\
NB-A & *af bitüm & Uzun dönem yaşlandırılmış \\
\hline
\end{tabular}




\subsection{Taramalı Elektron Mikroskobu (SEM)}

Saf ve SBS katkılı bitümlerin kırılmış yüzey morfolojileri yüksek vakumlu (5kV), Hitachi (Tokyo, Japonya) marka masaüstü tipi Taramalı Elektron Mikroskobu kullanılarak elde edilmiştir. Bitümlü malzemelerin yüzey morfolojisinin SEM kullanılarak incelenebilmesi için sıvı nitrojen yardımıyla soğutulup yüzey blok numunenin kırılması sağlanmalıdır. Böylece, saf bitüm ya da PMB numunelerinin zayıf bağlanma yaptığı yerlerin incelenmesi mümkündür. Numunelerin kırılma yüzeylerini morfolojik görüntülerini elde edebilmek için numunelerin sıvı nitrojen içerisinde yaklaşık 1 dakika bekletilerek donması sağlanmış ve en zayıf noktadan kopma eğiliminde olan donmuş PMB numunelerinin yüzey morfolojileri kıyaslanmıştır. Numune hazırlama aşamasında sıvı nitrojenin kullanılmasının sebebi, numunenin yüzey morfolojisini elde ederken herhangi bir plastik deformasyondan kaçınma gereksinimidir.

\subsection{Optik Mikroskop}

Deneysel çalışmalar süresince PMB numunelerinin morfolojik görüntüleri Leica DMEP Fluoresan Optik Mikroskobu kullanılarak gözlemlenmiştir. Görüntülerin kaydedilmesi mikroskoba bağlı Nikon Coolpix 4500 kamera ile $\times 40$ büyütme kullanılarak sağlanmıştır. Ayrıca, bitüm morfolojisinin en etkili şekilde elde edilmesini sağlayan mavi filtre ataşmanı da kullanılmıştır. Elde edilen görüntüler Image J programı kullanılarak işlenmiş ve farklı oranda SBS kopolimerinin bitüm fazındaki dağılımı araştırılmıştır. Numune hazırlama, PMB'lerin morfolojisini incelemede önemli bir rol oynayabilir. Yeterli miktarda bitüm $(3-5 \mathrm{~g})$ cam bir lam üzerine yerleştirilerek, gerekli inceliğe ulaşabilmesi amacıyla, $100^{\circ} \mathrm{C}$ sıcaklıklı 1sıtma tablasında 1 dakika bekletilerek numune hazırlama işlemi gerçekleştirilmiştir. Önceki çalışmalar farklı örnek hazırlamadan kaynaklanan morfolojilerdeki farklılıkları ortaya çıkabileceğini göstermektedir [29,30]. Bu sebeple, kıyaslama yapılabilmesi açısından, her bir numune aynı hazırlama koşullarına maruz bırakılmıştır.

\section{Deneysel Sonuçlar ve Tartışma}

Saf bitüm ve farklı oranlarda SBS kullanılarak hazırlanan PMB numunelerinin kırılmış yüzey morfolojik görüntüleri SEM kullanılarak incelenmiş ve elde edilen görüntüler Şekil 3-6'de sunulmuştur.
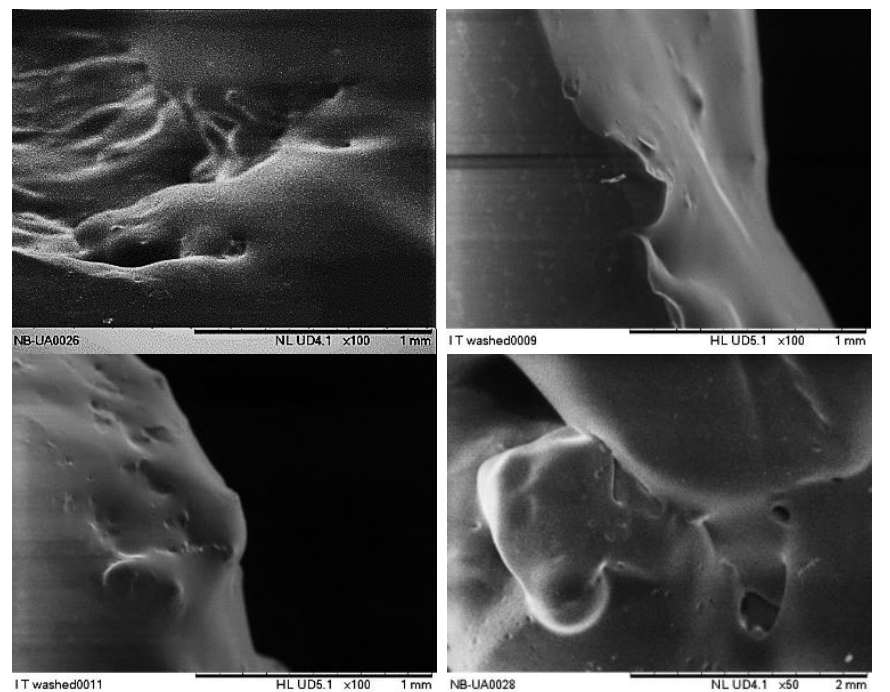

Şekil 3. Saf bitüme ait SEM ile elde edilen yüzey morfolojik görüntüleri 
Stiren-Butadiyen-Stiren İçeriğinin Bitümün Kırılmış Yüzey Morfolojisine Etkilerinin İncelenmesi
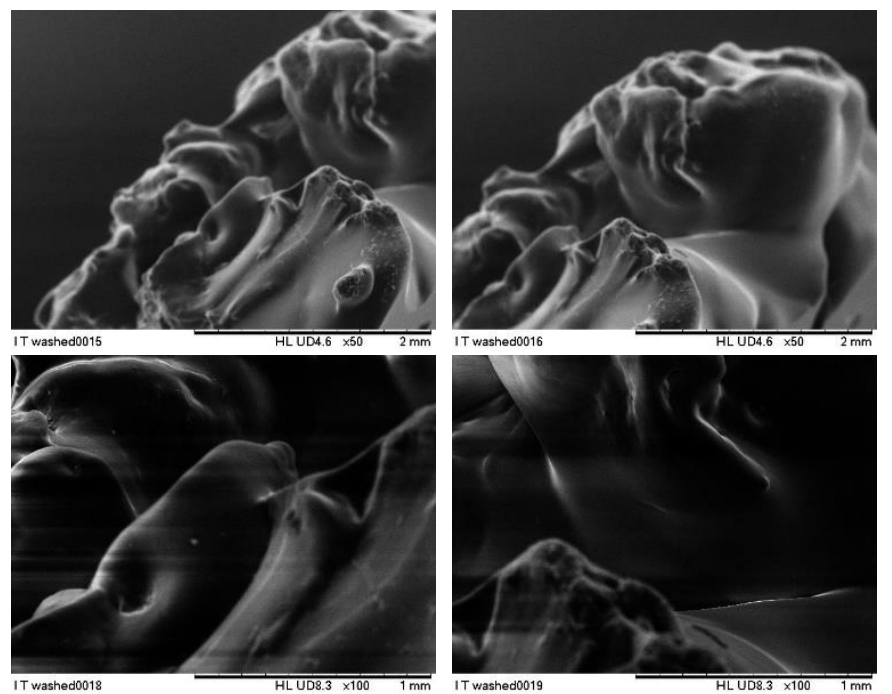

Şekil 4. \%4-UA numunesine ait SEM ile elde edilen yüzey morfolojik görüntüleri
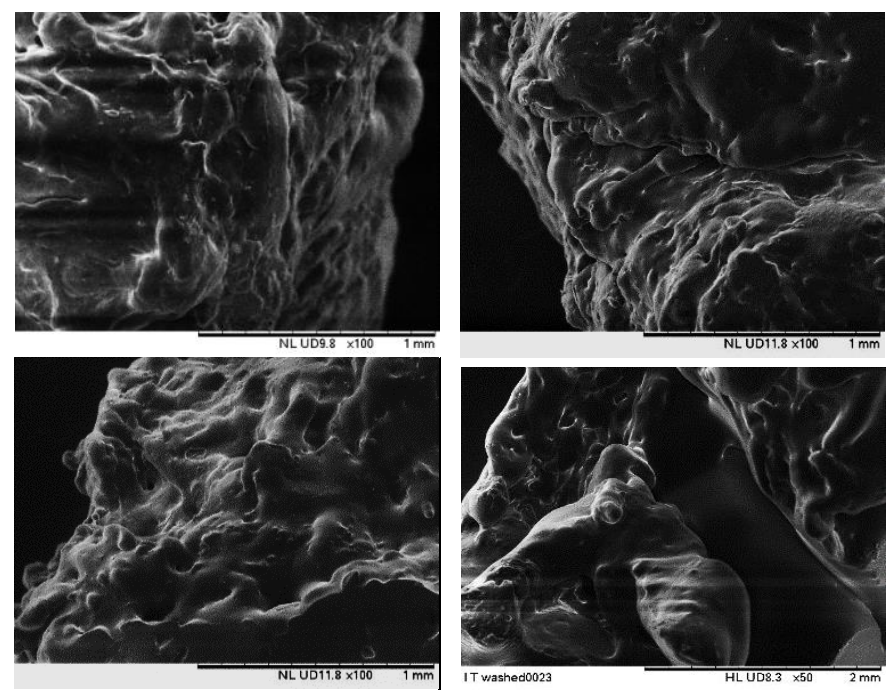

Şekil 5. \%5-UA numunesine ait SEM ile elde edilen yüzey morfolojik görüntüleri
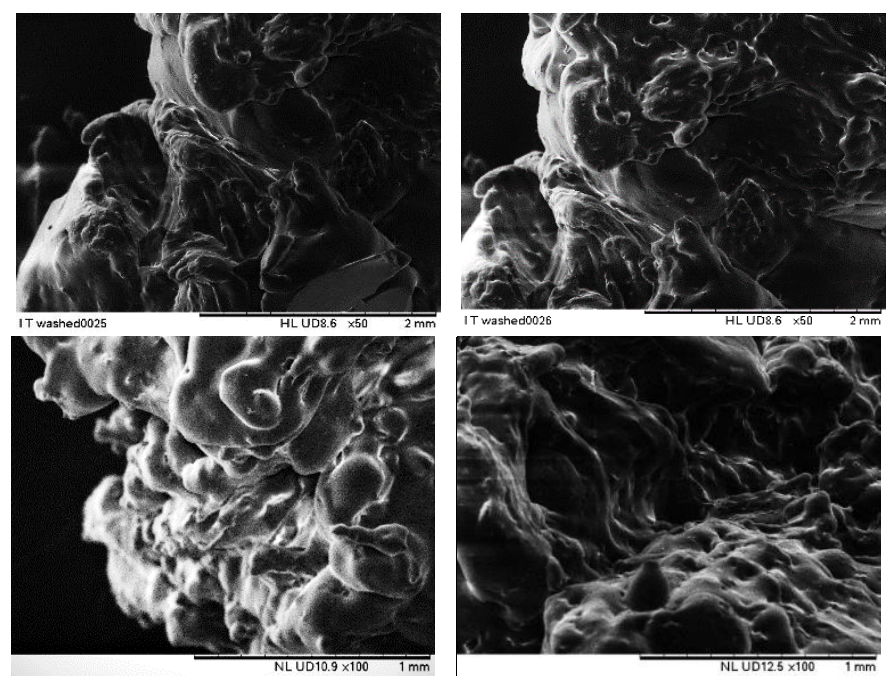

Şekil 6. \%6-UA numunesine ait SEM ile elde edilen yüzey morfolojik görüntüleri 554 
Şekil 3-6'dan da görülebileceği gibi, SBS katkılı PMB numunelerinin kırılmış yüzey morfolojileri, modifikasyon sonrasında meydana gelen çapraz bağlar sebebiyle, saf bitüme oranla daha pürüzlüdür. Benzer sebeple, PMB içeriğindeki SBS oranının artması oluşan çapraz bağ miktarını arttırmış ve bu da daha pürüzlü yüzey oluşumuna sebep olmuştur. Ancak, \%5-UA numunesi ve \%4-UA numunelerinde meydana gelen pürüzlülük artış1 \%5-UA ve \%6-UA numunelerinde artışa oranla daha azdır. Bunu daha iyi görebilmek amacı ile her bir numuneye ait görseller ImageJ programında incelenmiş ve numunelerin kırılma noktalarının köşeliliklerini gösteren görseller Şekil 7'de sunulmuştur.

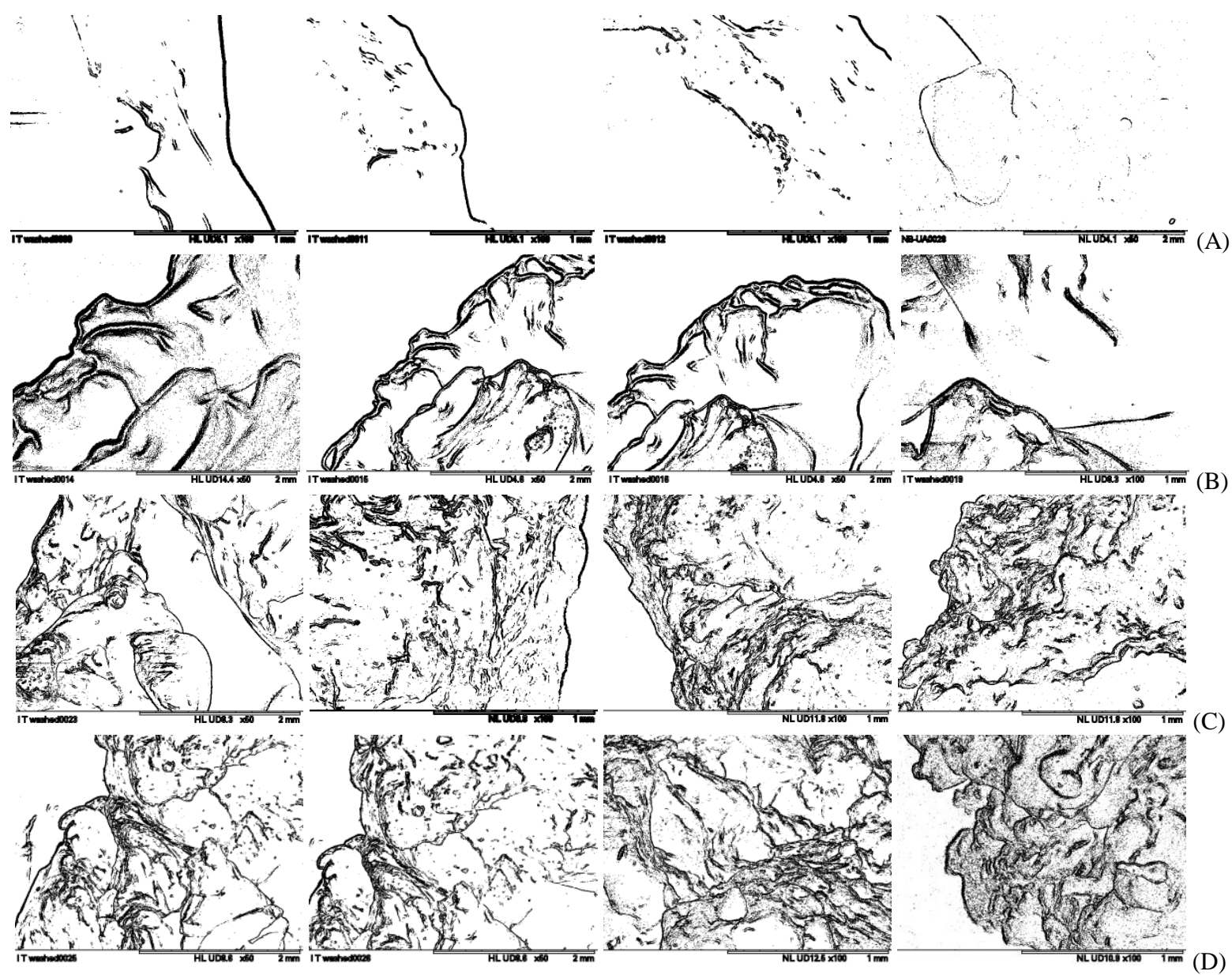

Şekil 7. Saf ve PMB numunelerine ait SEM ile elde edilen ikili yüzey morfolojik görüntüleri

(A) NB (B) \%4-UA (C) \%5-UA (D) \%6-UA

\%6-UA numunesinin \%5-UA numunesine göre çok belirgin olmayan pürüzlük artışına sebep olması şu bilgi ile aydınlatılabilir; \%5 oranında SBS kopolimeri kullanımı asfalt içeriğindeki belirgin miktar malten bileşenlerini emerek şiştiği için daha fazla SBS kullanımında bitüm içeriğinde yeterince şişmesini sağlayacak malten içeriği bulunmamaktadır [15]. Bu sebeple SBS miktarındaki artış, \%5 SBS kullanımının artmasıyla doğrusal bir şekilde artmamaktadır. $\mathrm{Bu}$ da oluşan çapraz bağ miktarını etkilemekte ve böylece; SEM incelemesi için oluşturulan yüzeylerdeki pürüzlülükteki artış miktarı daha düşük oluşmaktadır. PMB içeriğindeki SBS kopolimerinin bitüm malten fraksiyonlarını emerek şişmesi floresan mikroskop altında gözlemlenebilmektedir [31]. Bu sebeple, farklı içerikte SBS içeren PMB numuneleri floresan mikroskop ile incelenmiş ve her bir numuneye ait elde edilen morfolojik görüntülerden bazı örnekler Şekil 8'de sunulmuştur. Elde edilen görseller Image J programında işlenmiş ve kırılma yüzeylerini meydana getiren çapraz bağ miktarı ile doğrudan ilgili olan PMB içeriğindeki SBS hacimleri hesaplanmıştır ve veriler Tablo 5'de verilmiştir. Tablo 5'de belirtilen "nihai SBS miktarı" ifadesi bitüm ağırlığının \%4-5 ve 6'sı olacak şekilde eklenen SBS polimerinin bitümün yağlı bileşenlerini emmesi sonucu elde edilen PMB içeriğindeki SBS miktarıdır. 

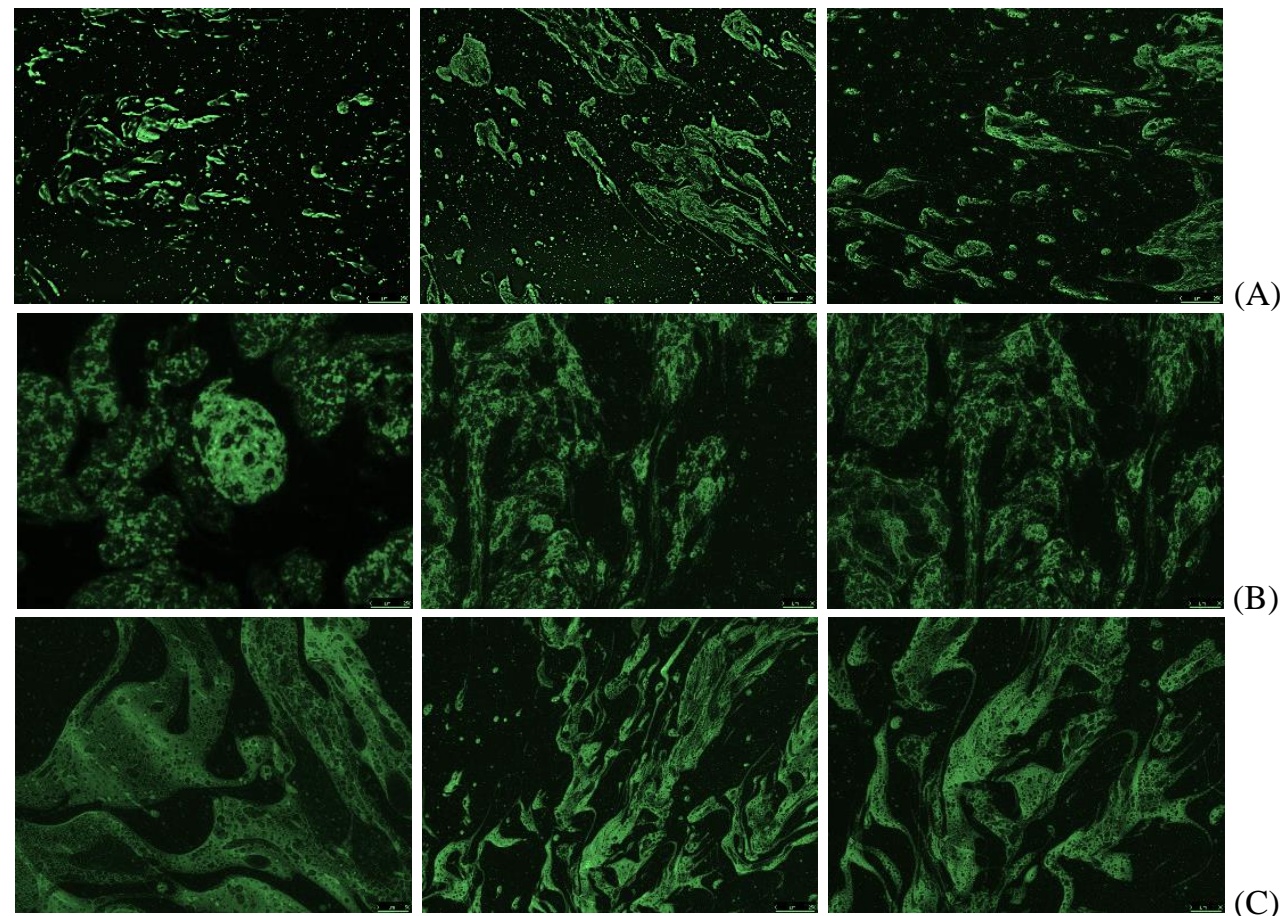

Şekil 8. PMB numunelerine ait Floresan optik mikroskop ile elde edilen morfolojik resimler (A) \%4-UA (B) \%5-UA (C) \%6-UA

Tablo 5. PMB içerisindeki SBS oranı ve şişme miktarları

\begin{tabular}{ccc}
\hline \multirow{2}{*}{ Numune Adı } & $\begin{array}{c}\text { PMB içerisindeki SBS dağılımı } \\
(\boldsymbol{\%})\end{array}$ & $\begin{array}{c}\text { SBS şişme oranı } \\
\text { (kullanılan SBS oranı/nihai SBS } \\
\text { miktarı) }\end{array}$ \\
\hline \%4-UA & 32,8 & 8,02 \\
\%5-UA & 42,6 & 8,52 \\
\%6-UA & 43,71 & 7,28 \\
\hline
\end{tabular}

Şekillerden de görülebileceği gibi, PMB numunelerinin morfolojik görüntüleri, farklı oranda SBS kopolimeri kullanılması ile değişmektedir. Ancak SBS oranının \%5'ten \%6'ya çıkarılması FM altında gözlemlenebilen PMB içeriğindeki SBS hacminde çok büyük bir artışa sebep olmamaktadır. Tablo 4'te de sunulduğu gibi \%4 SBS oranının \%5'e çıkarılması, bitüm içeriğindeki SBS hacminde \%10 gibi bir artışa sebep olmaktadır. Bu durum bitümün içeriğindeki malten miktarının emilerek SBS'in başlangıç hacminin 8-9 katına kadar şişmesine olanak verecek olması ile açıklanabilir. Fakat \%6 SBS miktarının kullanılması, SBS'in ancak 7,28 katına kadar şişmesine olanak vermektedir. Çünkü bitüm içeriğindeki malten miktarı \%6 SBS'in 8 katına şişmesini sağlayacak kadar yeterli değildir. Sonuç olarak, PMB içeriğindeki nihai SBS hacmi karışımın yaklaşık olarak \%43'ünü oluşturmaktadır. Diğer bir deyişle, \%5'ten daha yüksek oranda SBS kullanılsa bile, PMB içeriğindeki şişme miktarı azalacağı için buna bağlı olarak PMB içeriğindeki nihai SBS hacmi ciddi oranda değişmeyebilir. Böylece darbe altında kırılarak oluşan kırılma yüzeylerini meydana getiren çapraz bağ miktarı da çok değişmeyecektir. $\mathrm{Bu}$ durum, SEM görüntülerindeki \%6 SBS kullanılmasının yüzey morfolojisinde pürüzlülügünü̈n azalan miktarda artmasını açıklayabilmektedir.

Son olarak, numuneler uzun dönem yaşlandırılarak bağların zarar görmesi sağlanmış ve kırılma yüzey morfolojik görüntülerinin pürüzlülük değişimleri incelenmiş̧ir. Bitümlü malzemeler yaşlandıkça moleküler bağları maruz kaldıkları olumsuz hava koşulları ve trafik yükleri ile zayıf bağlara sebep olmaktadır. Bu sebeple, içeriğinde daha fazla bağ bulundurulan numunelerin daha pürüzlü yüzey morfolojilere sahip olmasını beklemek mümkündür. Uzun dönem yaşlandırılmış saf bitüm ve farklı oranlarda SBS içeren PMB numunelerine ait görseller Şekil 9'da sunulmuştur. 
(A)

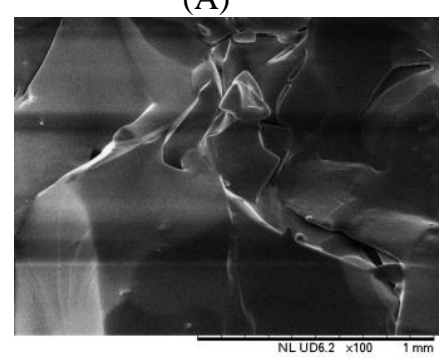

(C)

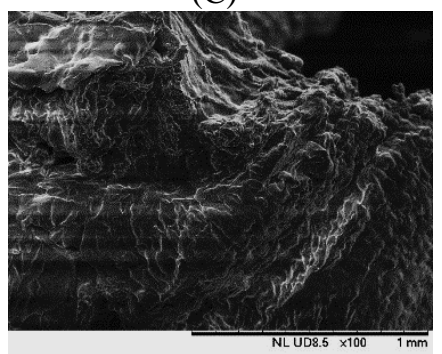

(B)

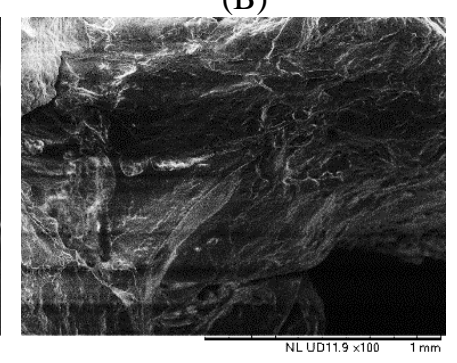

(D)

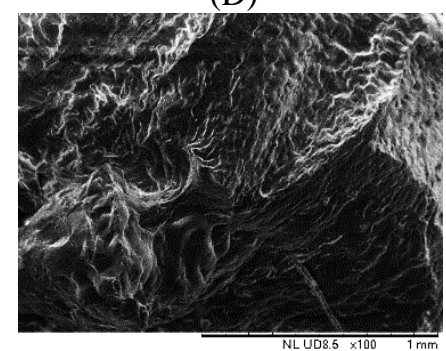

Şekil 9. (A) NB-A, (B) \%4-A, (C) \%5-A ve (D) \%6-A numunelerine ait yüzey morfolojik görüntüleri

Şekil 9'da görüldüğü gibi, görüntüler beklenen doğrultuda elde edilmiş ve PMB numunelerinde, saf bitüme oranla, bitüm ve SBS arasında oluşan çapraz bağ oluşumu ile meydana gelen artan bağ yapısından kaynaklı, daha pürüzlü yüzeyler elde edilmiştir. Yaşlandırılmamış numuneler ile uzun dönem yaşlandırılmış numunelerin kırılmış yüzey morfolojileri kıyaslandığında ise, yaşlanmış numunelerin daha küçük derinlikte pürüzlülükler elde ettiği görülmüştür. Bunun sebebi, kırılma çizgilerinin daha zayıf bağları takip etmesi ve numunelerin yaşlandırılmasının ardından PMB içeriğindeki tüm bağların zayıflamış olmasıdır. Tablo 5'de de belirtildiği gibi saf bitüm ile çalışmada kullanılan en az polimer içeriği olan \%4 SBS içeren numuneler arasında yaklaşık \%33'luk bir SBS hacmi farkı varken, $\% 4$ ile $\% 6$ arasında yaklaşık \%11'lik bir fark vardır. Uzun dönem yaşlandırmanın ardından çoklu karbon bileşeninden oluşan bitümün kendi bağları da zarar gördüğü için yüzey morfolojisindeki pürüzlülük artışının tek sebebi değişen SBS miktarı ile artan çapraz bağ oluşumları değildir. Ancak, SBS içeren PMB numunelerinin saf bitüme oranla daha fazla pürüzlülük oluşturduğunu söylemek mümkündür.

\section{Sonuçlar ve Öneriler}

Çalışma kapsamında, farklı oranlarda SBS kullanımının bitüm ve SBS arasında oluşan çapraz bağ oluşumlarından kaynaklı kırılma noktalarındaki yüzey pürüzlülükleri üzerindeki etkisinin SEM ve FM kullanılarak incelenmesinin ardından elde edilen sonuçlar aşağıdaki gibidir:

- SEM ile yapılan incelemelerde, PMB numunelerinde, bitüm ve SBS arasında meydana gelen çapraz bağ oluşumdan kaynaklı olarak, kırılmış yüzey pürüzlülüklerinin saf bitüme oranla daha fazla olduğu görülmüştür.

- PMB içeriğindeki SBS miktarının \%5'ten \%6'ya çıkarılması, \%4 oranından \%5'e çıkarılmasına kıyasla daha az pürüzlülük artışı meydana getirmektedir. Buna sebep olarak, \%5 oranında SBS kopolimeri kullanımının asfalt içeriğindeki malten bileşeninin neredeyse tamamını emerek şişmesi gösterilebilir. Sonuç olarak, çalışmada kullanılan bitümün yeterli malten içeriğinde olmamasından ötürü, \%5 den daha fazla SBS kullanımında yüzey pürüzlülüklerinde yüksek oranda artış görülmemektedir.

- Floresan mikroskop ile yapılan çalışmalar göstermiştir ki, SBS oranının \%5’ten \%6'ya çıkarılması PMB içeriğinde ciddi bir SBS hacmi artışına sebep olmamaktadır. Diğer bir deyişle, \%5'ten daha yüksek oranda SBS kullanılsa dahi, PMB içeriğindeki SBS hacminin şişme oranı azalacak ve nihai SBS miktarı ciddi oranda değişmeyecektir.

- Bitümün yaşlanması ile birlikte moleküller arası bağlar zayıflamakta bu da kırılmış yüzey morfolojilerinin daha pürüzlü olmasına sebep olmaktadır. Buna bağlı olarak, içeriğinde daha fazla bağ bulunduran PMB numuneleri saf bitüme kıyasla daha pürüzlü yüzeyler sağlamaktadır. Ancak, uzun dönem yaşlandırma işleminin ardından bitümün kendi bağlarının da zarar görmesinden kaynaklı olarak SBS oranının değişimi ile artan çapraz 
bağ miktarının yüzey morfolojik görüntüler üzerindeki değişime etkisini kesinlik içeren ifadelerle açıklamak mümkün değildir.

Elde edilen sonuçlar 1şığında gelecek çalışmalara yön vermesi açısından bazı öneriler de bulunulabilir:

- Çalışma kapsamında, bitümün içeriğindeki malten miktarının SBS şşsmesi üzerindeki etkileri ortaya konulmuştur. $\mathrm{Bu}$ durum, farklı penetrasyon sınıfındaki bitümler ve farklı Stiren Butadiyen içeren SBS kopolimerlerinin kullanılması ile daha kapsamlı olarak araştırılabilir.

- Çalışma kapsamında sadece taramalı elektron mikroskobu ve floresan optik mikroskop kullanılarak morfolojik incelemeler yapılmıştır. Konfokal lazer tarama mikroskobu, Elektron tarama mikroskobu, Atomik kuvvet mikroskobu gibi çeşitli görüntüleme cihazları ile de PMB numunelerinin morfolojik incelemelerinin yapılması halinde daha detaylı değerlendirme yapmak mümkün olabilecektir.

- SBS ilavesi ile oluşan çapraz bağlanmaların etkilerinin incelenmesi amacıyla morfolojik incelemelerin yanı sıra, PMB'nin kimyasal, yapısal ve hatta termal karakterizasyon incelemelerinin de yapılması gerekmektedir.

\section{Teşekkür}

Yazar, çalışma kapsamında kullanılan Floresan Optik Mikroskop mavi filtre ataşmanını DEÜ BAP 2018.KB.FEN.028 nolu Bilimsel Araştırma Projesi kapsamında temin ettiği için Dokuz Eylül Üniversitesi Rektörlüğüne teşekkür etmektedir.

\section{Kaynaklar}

[1] Boysen RB, Schabron JF. The automated asphaltene determinator coupled with saturates, aromatics, and resins separation for petroleum residua characterization. Energ Fuel 2013; 27(8): 4654-4661.

[2] Carrera V, García-Morales M, Navarro FJ, Partal P, Gallegos C. Bitumen chemical foaming for asphalt paving applications. Ind Eng Chem Res 2010; 49(18): 8538-8543.

[3] Liang M, Liang P, Fan W, Qian C, Xin X, Shi J, Guozhi N. Thermo-rheological behavior and compatibility of modified asphalt with various styrene-butadiene structures in SBS copolymers. Mater Design 2015; 88: 177-185.

[4] Navarro F, Partal P, Martınez-Boza F, Valencia C, Gallegos C. Rheological characteristics of ground tire rubber-modified bitumens. Chem Eng J 2002; 89(1-3): 53-61.

[5] Speight J. Petroleum Asphaltenes-Part 1: Asphaltenes, resins and the structure of petroleum. Oil Gas Sci Technol 2004; 59(5): 467-477.

[6] Masson J, Collins P, Robertson G, Woods J, Margeson J. Thermodynamics, phase diagrams, and stability of bitumenpolymer blends. Energ Fuel 2003; 17(3): 714-724.

[7] Collins J, Bouldin M, Gelles R, Berker A. Improved performance of paving asphalts by polymer modification (with discussion). In: Asphalt Paving Technology Conference; 4-6 March 1991; Seattle, New York. pp. 43-79.

[8] Lu X, Isacsson U. Modification of road bitumens with thermoplastic polymers. Polym Test 2000; 20(1): 77-86.

[9] Sengoz B, Isikyakar G. Evaluation of the properties and microstructure of SBS and EVA polymer modified bitumen. Constr Build Mater 2008; 22(9): 1897-1905.

[10] Zhu J, Birgisson B, Kringos N. Polymer modification of bitumen: Advances and challenges. Eur Polym J 2014; 54: 1838.

[11] Airey GD. Rheological properties of styrene butadiene styrene polymer modified road bitumens 2 . Fuel 2003; 82(14): 1709-1719.

[12] Larsen DO, Alessandrini JL, Bosch A, Cortizo MS. Micro-structural and rheological characteristics of SBS-asphalt blends during their manufacturing. Constr Build Mater 2009; 23(8): 2769-2774.

[13] Ouyang C, Wang S, Zhang Y, Zhang Y. Preparation and properties of styrene-butadiene-styrene copolymer/kaolinite clay compound and asphalt modified with the compound. Polym Degrad Stabil 2005; 87(2): 309-317.

[14] Polacco G, Stastna J, Biondi D, Zanzotto L. Relation between polymer architecture and nonlinear viscoelastic behavior of modified asphalts. Curr Opin Colloid In 2006; 11(4): 230-245.

[15] Kaya D, Topal A, McNally T. Correlation of processing parameters and ageing with the phase morphology of styrenebutadiene-styrene block co-polymer modified bitumen. Mater Res Exp 2019; 6(10),:105309.

[16] Kaya D, Topal A, Gupta J, McNally T. Aging effects on the composition and thermal properties of styrene-butadienestyrene (SBS) modified bitumen. Constr Build Mater 2020; 235: 117450.

[17] Kaya D, Topal A, McNally T. Relationship between processing parameters and aging with the rheological behaviour of SBS modified bitumen. Constr Build Mater, 2019; 221: 345-350.

[18] Schaur A, Unterberger S, Lackner R. Impact of molecular structure of SBS on thermomechanical properties of polymer modified bitumen. Eur. Polym. J 2017; 96: 256-265.

[19] Hernández G, Medina EM, Sánchez R, Mendoza AM. Thermomechanical and rheological asphalt modification using styrene- butadiene triblock copolymers with different microstructure. Energ Fuel 2006; 20(6): 2623-2626.

[20] E García RG. Effect of Stirring Speed in Hot Mixing Process of Modified Asphalt with SBS Copolymer on Polymeric Distribution and its Rheological Properties. London, England: Cambridge University Press, 2016. 
[21] Jiang Z, Easa SM, Hu C, Zheng X. Evaluation of new aspect of styrene-butadiene-styrene modified bitumens: Damping property and mechanism. Constr Build Mater 2020; 242: 118-185.

[22] Loeber L, Sutton O, Morel J, Valleton JM, Muller G. New direct observations of asphalts and asphalt binders by scanning electron microscopy and atomic force microscopy. J Microsc-Oxford 1996; 182(1): 32-39.

[23] Wilson A, Fuchs G, Scramoncin C, Martin D, Planche J. Localization of the polymer phase in bitumen/polymer blends by field emission cryo-scanning electron microscopy. Energ Fuel 2000; 14(3): 575-584.

[24] Kosma V, Hayrapetyan S, Diamanti E, Dhawale A, Giannelis EP. Bitumen nanocomposites with improved performance. Constr Build Mater 2018, 160: 30-38.

[25] Kumar K, Singh A, Maity SK, Srivastava M, Sahai M, Singh RK, Madhukar OG. Rheological studies of performance grade bitumens prepared by blending elastomeric SBS (styrene butadiene styrene) co-polymer in base bitumens. J Ind Eng Chem, 2016; 44: 112-117.

[26] Rasool R, Hongru Y, Hassan A, Wang S, Zhang H. In-field aging process of high content SBS modified asphalt in porous pavement. Polym Degrad Stabil 2018; 155: 220-229.

[27] Bell CA. Summary report on aging of asphalt-aggregate system: Strategic Highway Research Program Report National Research Council, Washington DC, USA: SHRP Report, 1989.

[28] Ahmedzade P, Yılmaz M, Yılmaz M. Bitümlü Bağlayıcıların Yaşlandırılmasında Kullanılan Deney Yöntemlerinin Karşılaştırılması. Erciyes Üniversitesi Fen Bilimleri Enstitüsü Fen Bilimleri Dergisi 2007; 23(1): 112-126.

[29] Kou C, Kang A, Zhang W. Methods to prepare polymer modified bitumen samples for morphological observation. Constr Build Mater 2015; 81: 93-100.

[30] Soenen H, Lu X, Redelius P. The morphology of bitumen-SBS blends by UV microscopy: an evaluation of preparation methods. Road Mater Pavement 2008; 9(1): 97-110.

[31] Bearsley S, Forbes A, Haverkamp RG, Direct observation of the asphaltene structure in paving-grade bitumen using confocal laser-scanning microscopy. J. Microsc, 2004; 215: 149-55. 